\title{
Laboreal
}

Volume $12 \mathrm{~N}^{\circ} 2$ | 2016

Equipamentos de Proteção Individual II

\section{O trabalho gerencial - do ponto de vista da atividade - na implementação de projetos de engenharia de alta complexidade: experiências e tecelagens}

El trabajo gerencial - del punto de vista de la actividad - en la ejecución de proyectos de ingeniería de gran complejidad: experiencias y tejidos

Le travail managérial - du point de vue de l'activité - l'exécution des projets d'ingénierie très complexes: expériences et tissages

Managerial work - the point of view of activity - in executing of highly complex engineering projects: experiences and weavings

\section{Rose Mery dos Santos Costa Leite}

\section{OpenEdition}

Journals

\section{Edição electrónica}

URL: http://journals.openedition.org/laboreal/2669

DOI: 10.4000/laboreal.2669

ISSN: 1646-5237

\section{Editora}

Universidade do Porto

\section{Refêrencia eletrónica}

Rose Mery dos Santos Costa Leite, «O trabalho gerencial - do ponto de vista da atividade - na implementação de projetos de engenharia de alta complexidade: experiências e tecelagens », Laboreal [Online], Volume 12 N² | 2016, posto online no dia 01 dezembro 2016, consultado o 24 setembro 2020. URL : http://journals.openedition.org/laboreal/2669 ; DOI : https://doi.org/10.4000/ laboreal.2669

Este documento foi criado de forma automática no dia 24 setembro 2020.

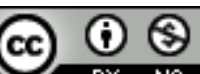

Laboreal está licenciado com uma Licença Creative Commons - Atribuição-NãoComercial 4.0 Internacional 


\section{O trabalho gerencial - do ponto de vista da atividade - na implementação de projetos de engenharia de alta complexidade: experiências e tecelagens}

El trabajo gerencial - del punto de vista de la actividad - en la ejecución de proyectos de ingeniería de gran complejidad: experiencias y tejidos

Le travail managérial - du point de vue de l'activité - l'exécution des projets d'ingénierie très complexes: expériences et tissages Managerial work - the point of view of activity - in executing of highly complex engineering projects: experiences and weavings

Rose Mery dos Santos Costa Leite

\section{REFERÊNCIA}

Leite, R.M.S.C. (2014). A atividade gerencial em empreendimentos: experiências e tecelagens. Tese de Doutoramento em Serviço Social, Escola de Serviço Social, Universidade Federal do Rio de Janeiro, Rio de Janeiro.

\section{NOTA DO EDITOR}

http://dx.doi.org/10.15667/laborealxii0216rclpt Manuscrito recebido em: fevereiro/2016

Aceite após peritagem: setembro/2016 


\section{Introdução}

1 Esta tese teve como campo empírico uma empresa pública do Brasil, do segmento de energia, especificamente o setor de petróleo e gás, marcado por uma "tradicional" dupla face, pública/privada, que foi, historicamente, se constituindo pela proximidade de vínculo entre a vida política nacional e a realidade empresarial. Caracteriza-se, por vezes, como uma típica organização de Estado, reforçando a sua face pública de ser dinamizadora do desenvolvimento do país, porém em outros períodos o que se evidencia é a sua face privada que está atrelada à lógica da racionalidade empresarial, orientada à reprodução ampliada de capital. É uma corporação complexa, segmentada, hierarquizada, reconhecida internacionalmente pela competência técnica e um saberfazer específico (não obstante graves problemas que vem passando nos últimos anos), que traz em sua cultura traços de relações baseadas em uma estrutura verticalizada de poder e orientada por um viés disciplinador (Scaletsky, 2003; Leite, 2009; Felipe, 2010).

2 O foco central da investigação foi buscar compreender - do ponto de vista da atividade - a dimensão da gestão cotidiana dos gerentes responsáveis pela implementação da carteira de projetos de engenharia dessa empresa. Tais projetos tratam de empreendimentos industriais de alta envergadura e complexidade, tanto pela dimensão econômica e pelo volume de negócios, quanto pela mobilização de enorme contingente de profissionais das mais diversas especialidades, assim como uma múltipla rede de diferentes atores com os mais distintos interesses.

3 A depender das características de cada projeto, de seu porte, grau de complexidade, nível tecnológico, coeficientes de inovação, indicadores e metas, dentre outros requisitos, incluindo o seu ciclo de vida (desenvolvimento, construção/execução e produção/operação), será criada uma nova gerência no organograma com a atribuição de realizar o gerenciamento de um ou mais projetos. Trata-se de estruturas gerenciais transitórias, que estão atreladas à temporalidade dos projetos, variando de acordo com a evolução dos mesmos, cronogramas previstos, implicações legais, licenciamentos etc. Podem estar localizadas em áreas administrativas ou operacionais, em instalações da própria empresa ou de empresas prestadoras de serviços, no país ou no exterior, com equipes mistas formadas por trabalhadores próprios (contratados via concurso público), e por prestadores de serviços de empresas terceiras. Esse cenário implica uma dinâmica e ritmos próprios, um processo cíclico, pois as equipes são estruturadas para a execução de um projeto e ao final da etapa de conclusão, estas são completamente desfeitas.

4 A gestão cotidiana dos projetos de engenharia, desde sua gênese até a etapa de operação da instalação industrial, é perpassada por inúmeras variabilidades e imprevisibilidades, sustentada por um patrimônio de saberes (científicos e da prática) que foi sendo construído ao longo da história da empresa de modo a compatibilizar exigências empresariais de ciclos de implantação cada vez mais rápidos e de menor demanda de recursos. 


\section{A caixa de ferramentas teórico-metodológicas}

5 A análise do trabalho do gerente em empresas que operam sistemas sócio-técnicos complexos envolve um campo investigativo e de intervenção técnica que associam, de forma estreita, investigação, formação e ação (Teiger, Laville \& Duraffourg, 2004). Por vezes, os saberes desenvolvidos pelos gerentes são "invisíveis" para eles próprios, tratando-se assim de conhecimentos "inconscientes e incorporados" e com grandes dificuldades de verbalização pelos mesmos. Entende-se ser fundamental ter como pressuposto que "o adulto em formação não é uma 'tábua rasa' mas um sujeito 'aprendente' ativo e reflexivo” (Lacomblez \& Teiger, 2007, p. 598).

6 A opção teórico-metodológica adotada tem como referência pressupostos éticoepistemológicos de uma linhagem de pensadores materialistas que compreendem a atividade humana como central na produção, (re)produção e transformação das sociedades e dos humanos, bem como no seu desenvolvimento e em sua luta pela saúde.

7 Assim, toda situação de trabalho é "sempre em parte, e esse em parte é sempre imprevisível, aplicação de um protocolo e experiência ou encontro de encontros" (Schwartz, 2010, p. 42). Nesse enquadramento, a produção da tese recebeu as influências da démarche ergológica (Schwartz, 2000; 2010), e das abordagens clínicas da Ergonomia da Atividade (Guérin, Laville, Daniellou, Durraffourg, \& Kerguelen, 2001; Falzon, 2007), da Psicodinâmica do Trabalho (Dejours, 2012; 2013), e da Clínica da Atividade (Clot, 2006; 2010) que possibilitou trazer para o campo de debates a articulação macro-micro na análise das atividades presentes no trabalho do gerente, cujas normas estão poderosamente atravessadas por um mundo de interesses e valores conflitantes.

8 A proposição é de que a caixa de ferramentas tenha referências para pensar outro modo de abordar o trabalho dos gerentes. Parte da premissa de que toda construção teóricometodológica ao mesmo tempo em que exige rigor científico, não é dada a priori, nem à revelia das condições singulares do estudo em questão e do campo de relações em que se dá. A análise não tem a pretensão de esgotá-las, mas de promover a interlocução dos conceitos que podem contribuir para a compreensão do trabalho gerencial, sob o ponto de vista da atividade.

9 É de se destacar a vinculação institucional da autora da tese, ao campo empírico, uma vez que era gerente setorial na empresa em foco. Essa implicação (Lourau,1990), considerando a condição híbrida de investigadora e gerente revelou-se um importante ingrediente no processo, por um lado demandando uma permanente atenção ao rigor epistemológico e teórico-metodológico, por outro revelando-se fator determinante para a produção de conhecimento.

10 Durante o itinerário de investigação, considerando as particularidades do terreno e de seus protagonistas, o posicionamento de hibridismo da investigadora e os objetivos da tese, a identificação de uma abordagem metodológica que congregasse esses fatores foi uma questão que contribuiu para o debate sobre a adoção de uma alternativa metodológica, junto aos gerentes, que não se limitasse a recolha de dados, e sim que suscitasse o estabelecimento de uma relação dialógica mobilizadora da expressão das experiências vividas da sua própria atividade.

11 O Método de Reconstituição Biográfica Centrada no Trabalho concebido por Ramos (2010) foi a opção vislumbrada, naquele momento, pois mostrava-se fomentador da 
dinâmica pretendida entre a investigadora e os gerentes. Ele foi potencializador para a compreensão das situações de trabalho, na medida em que se configurou como um processo de intervenção, em uma abordagem clínica (uma vez que partiu de questões situadas no trabalho específico, mas que o transcendiam), suscitando o surgimento de significados e sentidos das vivências cotidianas. 0 método está assentado na articulação entre dois instrumentos que foram reconfigurados à luz das especificidades da tese, quais sejam: a) as "Entrevistas de Reconstituição Biográfica" (Ramos, 2010) que correspondem a uma forma de entrevista semiestruturada, de caráter biográfico, sendo realizadas com o mesmo gerente, diferentes entrevistas. No sentido de registrar uma diferenciação em relação às técnicas que hegemonicamente são empregadas nesse terreno adotou-se a denominação de "conversa" [1], ao invés de entrevista. Na primeira conversa foi estabelecido um acordo de trabalho/de cooperação, ratificada a proposta de estudo, estabelecidaas bases de confidencialidade, apresentado o dispositivo de pesquisa, e foi iniciada a conversa. Nas conversas seguintes, que teve uma variabilidade de uma a três, a partir da restituição da conversa anterior, os diálogos prosseguiram, percorrendo a linha cronológica, mas não necessariamente de forma linear. A "Entrevista de Reconstituição Biográfica" tem a finalidade de (re)construir o percurso de vida, onde são escolhidas as experiências vividas e "arquivadas" relacionadas à realidade atual vivida (Ramos, 2010), uma vez que a "biografia está sempre completa sem o jamais estar" (Ramos, 2010); b) um dispositivo, concebido como um suporte gráfico, com a função de ser um guia orientador e de apoio à realização das conversas que recebeu nessa investigação a denominação de "Teia da Vida". Esse dispositivo inclui dois tipos de dados: os "heterobiográficos e autobiográficos" (Ramos, 2010, p. 110). Os dados "heterobiográficos" são oriundos de fontes documentais, como por exemplo, relatórios, sistemas e outros mecanismos que estejam relacionados com a questão em estudo. E os dados "autobiográficos" que são provenientes das conversas junto aos protagonistas envolvidos na investigação.

A estrutura central do dispositivo "Teia da Vida" parte de uma linha temporal, onde são agrupados blocos de linhas horizontais tanto na parte superior quanto inferior do tempo demarcado. Foram abordados nove temas nesse dispositivo, de modo a atender aos objetivos do estudo, sendo três deles referidos aos dados "heterobiográficos" (percurso de atualização formativa, percurso preparatório e percurso gerencial) e seis relativos aos dados "autobiográficos" (atividades diárias/eixos operacionais, projetos, dificuldades/facilidades, equipes, história de saúde e referências). 0 dispositivo "Teia da Vida" se constituiu como um facilitador para a reconstituição biográfica, por apresentar uma estrutura e linguagem visual que está referida a uma lógica mais tecnicista e a traços identitários com o que é corriqueiro nos processos de trabalho desses gerentes.

13 A proposição de investigação foi submetida à aprovação da empresa que destacou a relevância da temática e a originalidade do dispositivo.

O universo abarcado pela pesquisa empírica totalizou 53 gerentes com a atribuição de implementação de empreendimentos, sendo todos concursados, com, no mínimo, graduação em engenharia, nas mais diversas especialidades, sendo $81 \%$ com idade entre 40 e 62, e 71\% com mais de 19 anos de permanência na empresa. Participaram da investigação sete gerentes, do sexo masculino, com larga experiência, variando de 27 a 38 anos de trabalho na empresa e de 14 a 25 anos no exercício gerencial. De modo a resguardar a confidencialidade desses gerentes não foi possível explicitar outras 
informações sobre o perfil. Todas as conversas foram registradas, em áudio, com prévia autorização dos mesmos.

Os convites foram realizados presencialmente, por contato telefônico ou por email, sendo que nesse momento foram apresentadas a justificativa e os objetivos do estudo.

Foram construídos sete diferentes dispositivos "Teia da Vida", uma vez que estes são instrumentos individuais.

o "Método de Reconstituição Biográfica Centrada no Trabalho" mostrou-se uma via potencializadora de mobilização subjetiva, na medida em que os diálogos produzidos não se referem a relatos de experiências a partir de uma trajetória de trabalho linear, criando-se possibilidades de que as respectivas histórias narradas possam ser (re)contadas com base em novas elaborações, explicações e relações com outros fatos ou eventos ocorridos, que reverberam-se com a realidade vivida e atual.

18 Todo material proveniente das conversas foi transcrito integralmente, a fim de garantir o máximo de fidedignidade aos registros constantes nos áudios.

\section{Análise e discussão dos resultados}

19 No processo analítico buscou-se colocar em sinergia as referências apresentadas no quadro teórico-metodológico e a análise dos materiais presentes nos discursos dos gerentes, privilegiando-se o contexto dialógico. Implicou a constituição de várias categorias emergentes dos diálogos, onde foram acionados os nove campos temáticos do dispositivo "Teia da Vida".

20 A análise revela referências sobre os diversos modos de reconstrução individual e coletiva desses gerentes no decorrer da história da empresa e do gerenciamento dos projetos de engenharia; destacou a importância da natureza nômade da atividade determinada pelos projetos de engenharia; explicitou o distanciamento entre as prescrições/o arcabouço técnico e as atividades; evidenciou a multiplicidade dos engendramentos que envolvem a gestão de contratos e das equipes; apresentou a diversidade de recursos linguageiros de natureza epopeica como uma alternativa para expressar a gestão da atividade gerencial cotidiana; e propiciou que as fontes de inspiração presentes e atuais fossem explicitadas.

21 Os resultados mostram que se trata de um trabalho cujas atividades exigem disponibilidade dos profissionais para estar, ao longo dos anos de profissão, em um permanente processo territorial migratório. Essa característica impacta as relações sociofamiliares, demandando que toda a vida seja governada por essa desterritorialização sistemática. Por parte dos gerentes existe uma busca de naturalização desse processo, que sinaliza para a adoção de uma estratégia defensiva que intensifica o valor e a importância do trabalho realizado e dos respectivos ganhos decorrentes, minimizando, por conseguinte, os custos oriundos da complexidade das situações e os impactos negativos em suas vidas.

22 Cada gerente foi encontrando modos singulares de aprender com as exigentes experiências migratórias com as quais foi se defrontando. Na gestão de suas atividades foi buscando compatibilizar o atendimento aos requisitos de qualidade e às expectativas empresariais e, ao mesmo tempo lidar com os insucessos diante dos desafios colocados e a dinâmica da vida fora do trabalho em suas dimensões simbólicas, relacionais e psicológicas. 

política empresarial, em curso, que vem amplificando e valorizando a lógica procedimental para além do é requerido tecnicamente. Explicitam que esse é um processo que gera desqualificação e esvaziamento da complexidade imbricada nas atividades gerenciais em foco, tratando-as de forma simplista, como se fosse possível acessar por meio de um manual toda a mobilização da inteligência astuciosa existente na atividade humana. Trata-se em negar a riqueza da potência da vida ou a igualá-la a um modo ou a uma rotina, onde o trabalho vivo não precisasse existir.

Os gerentes, cotidianamente, se defrontam com situações de trabalho variadas, saturadas de imprevisibilidades, a partir das quais tem que se empenhar, detectando/ interpretando/equacionando as questões emergentes, criando soluções, inventando artimanhas e incorporando sutilezas. A inteligência mobilizada frente às situações reais de trabalho e que engendra soluções inéditas para os problemas, as variabilidades e os imprevisíveis, exigem zelo (Dejours, 2012; 2013). Essa inteligência criadora, enraizada no corpo inteiro na relação sensorial e perceptual do corpo (não apenas do cérebro) com a tarefa é referida à malícia, à esperteza, à astúcia, que na mitologia grega referese à deusa Métis [2] (Dejours, 2012; Détienne, \& Vernant, 2008). Algo que Schwartz (2000; 2011) vem denominando corpo-si.

Nesse sentido, a gestão de contratos, apesar de estar pautada por prescrições determinantes nessa atividade, demanda, sob o ponto de vista de seus protagonistas, um tipo de inteligibilidade concebida na vivência da prática e um processo de formação que vai, paulatinamente, sendo configurado e aprendido ao longo da experiência adquirida em cada projeto desenvolvido. Um patrimônio fruto desse campo experiencial que inclui vários aspectos, quais sejam: a) multiplicidade e complexidade de contratos que envolvem várias empresas nacionais e/ou internacionais terceiras, prestadoras de serviços hiperespecializados; b) questões técnicas relacionadas a indicadores quantificáveis, de acordo com métricas nacionais e/ou internacionais, especificas do negócio; e c) decisões dos níveis hierárquicos superiores, que implicam a integração de múltiplas temáticas, de âmbito interno e externo, considerando dentre outras a natureza pública da empresa contratante, terreno da investigação. Trata-se, cotidianamente, de relações com empresas contratadas que explicitam permanentes e contundentes debates de normas, onde circulam um mundo de valores. Foi possível compreender que a experiência desses gerentes aponta para a exigência de uma atividade dialógica que deve ser priorizada para o estabelecimento de negociações cotidianas imprescindíveis, de modo os problemas sistematicamente possam ser superados, tendo em vista a singularidade de cada situação de trabalho e os modos operatórios e gestionários a serem (re)normatizados (Schwartz, 2000) e (re)normalizados.

Apesar do modelo gerencial vigente, perpassado por expressões de autoritarismo, dar sinais de hegemonia, os gerentes marcam em suas falas posicionamentos divergentes entre as suas respectivas visões, que priorizam o diálogo e o debate, e as práticas em curso. As narrativas apresentam um trabalho perpassado por vários atributos de pioneirismo, força, capacidade de "guerrear e de sentir-se Deus", símbolos que remetem à virilidade (e a sistemas defensivos psíquicos por ela marcados), ao mesmo tempo requerendo astúcia, uma inteligência virtuosa e polarizada pelo feminino (Dejours, 2012). Os diálogos enfatizam, para além das normas antecedentes, as alternativas apreendidas originárias da inteligência astuciosa, destacando-se a 
dimensão coletiva do trabalho, representada pelas relações de cooperação. Assim configurando-se caminhos estratégicos possíveis para aumentar a confiabilidade junto aos demais gerentes, às equipes e às empresas prestadoras de serviços, de modo que o investimento nessa tecelagem pudesse contribuir para o objetivo maior desses gerentes: "ter a obra concluída dentro do previsto".

\section{Considerações finais}

27 Diante das situações reais de trabalho, estes gerentes revelam atualizar seu agir em competência (Schwartz, 2010), desenvolvendo e mobilizando outras, encontrando saídas e soluções para os imprevistos e as variabilidades. Os diálogos estão demarcados por questões vinculadas a uma mobilização subjetiva produzida e por uma linguagem gerencial metafórica, em que definem a execução dos projetos de engenharia como um verdadeiro "campo de batalha ou de guerra" e se autodenominam de diferentes formas: como "Deus", "César, o imperador", ou o personagem "herói de guerra, Rambo".

Os materiais discursivos desses gerentes referem-se às experiências vividas ao longo da implementação de diferentes projetos de engenharia que engendram uma trajetória gerencial não linear, mas embrenhada em uma verdadeira "teia". Essa tecelagem foi estruturada por traços de uma gestão autoritária e hierarquizada que permeou o processo histórico da empresa e pelas interferências socioeconômicas, políticas e culturais do país. Trata-se de um cotidiano vivo marcado por características peculiares e adversas da natureza do negócio, relativo à indústria extrativista, "retirar riquezas energéticas, perfurando e adentrando as entranhas da terra". E, também por diálogos de enfrentamentos que assumem o desenho de um cenário aguerrido e bélico instituídos por expressões e metáforas que sinalizam para a faceta gerencial como um "combatente", relativo a um tipo de resignação heroica e uma atividade linguageira, fruto de uma produção social e histórica vivida.

Os protagonistas das atividades em análise salientam para a riqueza e fecundidade do processo de aprendizagem e desenvolvimento ao longo de suas trajetórias profissionais, uma vez que estas não se restringem ao que é realizado, mas também às dificuldades e enfrentamentos, aos riscos, a um desenvolvimento histórico que tece uma trama que se entrelaça entre as dimensões profissional e pessoal e que privilegia as respectivas vivências. As relações dialógicas estão sempre presentes e de forma permanente, com outros gerentes que já tinham alguma experiência, de modo a se construir um processo desenvolvimental durante a implantação de uma obra. Destacam que em um processo de formação futura a ser empreendido, a linguagem e a comunicação devem ocupar lugar de destaque na produção de saberes, considerando o modo como as coisas são ditas para buscarmos compreendê-las como são pensadas e concretizadas (Santos, \& Lacomblez, 2001/2002).

30 A abordagem centrada no itinerário de vida e de trabalho nesse estudo se configurou como um processo de intervenção, como um método clínico, na medida em que partiu de questões situadas no trabalho. Esse recurso teórico-metodológico pode se constituir em uma via de acesso para outras investigações nesse terreno ou em outros da mesma natureza, que também estejam perpassados por uma lógica racional e quantitativa.

31 O dispositivo "Teia da Vida" por ter uma "arquitetura" que o vinculou à realidade de trabalho desses gerentes criou condições para que os diálogos circulassem sem estranheza e como um espaço disparador de uma mobilização subjetiva. A narrativa do 
"contar" os encheu de orgulho pelo trabalho realizado e pelas estratégias acionadas durante os seus enfrentamentos, uma vez que ninguém havia se interessado e lhes solicitado a "contar" sobre suas histórias até aquele momento.

Explorar o trajeto de vida no trabalho, retomando vivências passadas, representou para estes gerentes como uma primeira experiência de confrontação consigo mesmo e com os eventos que foram destacados ao longo das conversas, se caracterizando como um estímulo à reflexão, ao compartilhamento e ao diálogo sobre a experiência vivida $\mathrm{e}$ vívida trazida à memória e a realidade atual, o que evidencia para a potencialidade desse estudo.

Os resultados desse estudo sugerem que o processo de formação gerencial, tendo em vista os referenciais da literatura da Administração e das "ciências da gestão" de base conceitual mecanicista e tecnocrática, assim como a adoção de referências cognitivocomportamentais para abordar as questões relativas ao humano, seja revisto.

Os diálogos expressam que a via de formação gerencial empregada pela empresa mostra-se insuficiente para atender às metas de produtividade, segurança e qualidade no trabalho, diante das exigências e complexidades das situações reais. Os gerentes assinalam para a necessidade de constituição de caminhos que promovam o debate, que congreguem os esforços coletivos e que coloquem em sinergia o "trabalhar juntos" em situações de trabalho.

\section{BIBLIOGRAFIA}

Clot, Y. (2006). A Função Psicológica do Trabalho. Petrópolis-RJ: Vozes.

Clot, Y. (2010). Trabalho e Poder de Agir. Belo Horizonte: Fabrefactum.

Dejours, C. (2012). Trabalho vivo. Brasília: Paralelo 15.

Dejours, C. (2013). o fator humano. Rio de Janeiro: FGV, $2^{\mathrm{a}}$ ed.

Détienne, M., \& Vernant, J. (2008). Métis: as astúcias da inteligência. São Paulo: Odysseus.

Falzon, P. (2007). Ergonomia. São Paulo: Edgard Blücher.

Felipe, E. S. (2010). Mudanças institucionais e estratégias empresariais: a trajetória e o crescimento da Petrobras a partir da sua atuação no novo ambiente competitivo (1997-2010). Tese de Doutorado. Economia. Universidade Federal do Rio de Janeiro, Rio de Janeiro.

Guérin, F., Laville, A., Duraffourg, J., \& Kergelen, A. (2001). Compreender o trabalho para transformálo: a prática da Ergonomia. São Paulo: Edgard Blücher.

Lacomblez, M., \& Teiger, C. (2007). Ergonomia, formações e transformações. In: P. Falzon (Org.). Ergonomia (587-599). São Paulo: Edgard Blücher.

Leite, R. M. S. C. (2009). Bandeirantes do Mar: a identidade dos trabalhadores das plataformas de petróleo. Rio de Janeiro: Intertexto.

Lourau, R. (1990). Implication et surimplication. Revue du Mauss, n.10. 
Ramos, S. (2010). Envelhecimento, Trabalho e Cognição: do laboratório para o terreno naconstrução de uma alternativa metodológica. Lisboa: Fundação Calouste Gulbenkian.

Santos, M., \& Lacomblez, M. (2001/2002). Discutir o trabalho, fazer sabendo: Projecto de formação profissional de adultos. Cadernos de Consulta Psicológica, 17/18, 305-311.

Scaletsky, E. C. (2003). o patrão e o petroleiro : um passeio pela história do trabalho na Petrobras. Rio de Janeiro: Relume Dumará.

Schwartz, Y. (2000). Le paradigme ergologique ou un métir de Philosophe. Toulouse: Octarès.

Schwartz, Y. (2010). Trabalho e Ergologia. In Y. Schwartz, \& L. Durrive (Orgs.) Trabalho e Ergologia: conversas sobre a atividade humana. Niterói-RJ: EDUFF, $2^{\underline{a}}$ ed. ampliada.

Schwartz, Y. (2011). Pourquoi le concept de corps-soi? Corps-soi, activité, expérience. Travail et Apprentissages, 7, 148-177.

Teiger, C., Laville, A. , \& Duraffourg, J. (2004). Trinta anos depois: reflexão sobre uma história das relações entre pesquisa em ergonomia e ação sindical na França (o caso das operárias do setor eletrônico entre 1965 e 1975). In M. Figueiredo, M. Athayde, J. Brito, \& D. Alvarez. (Orgs.) Labirintos do trabalho: interrogações e olhares sobre o trabalho vivo. Rio de Janeiro: DP\&A.

\section{NOTAS}

1. Athayde (2010, em comunicação pessoal) vem preferindo denominar o que vem sendo também chamado de "entrevistas dialógicas" de "conversas sobre o trabalho". Enquanto a entrevista está perpassada por certo "grau" de formalidade, a conversa pressupõe algo mais informal, intuitivo, fortemente relacional, remetendo a um encontro ou a um "bate-papo".

2. Conforme a Psicologia Histórica, os estudos de Détienne e Vernant (2008) sobre a Grécia Antiga mostram na mitologia a figura da deusa Métis, caracterizada pelos fecundos conselhos práticos, dada sua astúcia, a Zeus (de quem teria sido sua primeira esposa). Esse conceito vincula-se à figura do feminino e se refere a um tipo de inteligência que aborda a interpretação, a improvisação, a astúcia, a criação, a invenção, o disfarce, a subversão e a transgressão. É uma inteligência da ação que demanda o engajamento de todo o corpo e subjetividade, no esforço de enfrentamento das situações diante do inesperado.

\section{AUTOR}

\section{ROSE MERY DOS SANTOS COSTA LEITE}

Petróleo Brasileiro S.A. - Avenida Henrique Valadares, 28, 9ํandar, Centro, Rio de Janeiro, Brasil, CEP 20.231-030

rose.milk@yahoo.com.br 